Utah State University

DigitalCommons@USU

\title{
$2-2013$
}

\section{Feasibility of High-Density Climate Reconstruction Based on Forest Inventory and Analysis (FIA) Collected Tree-ring Data}

\author{
R. Justin DeRose \\ U.S. Forest Service \\ Shih-Yu (Simon) Wang \\ Utah State University \\ John D. Shaw \\ U.S. Forest Service
}

Follow this and additional works at: https://digitalcommons.usu.edu/wadr

Part of the Environmental Sciences Commons

\section{Recommended Citation \\ DeRose, R. Justin; Wang, Shih-Yu (Simon); and Shaw, John D., "Feasibility of High-Density Climate Reconstruction Based on Forest Inventory and Analysis (FIA) Collected Tree-ring Data" (2013). Wasatch Dendroclimatology Research. Paper 7. \\ https://digitalcommons.usu.edu/wadr/7}

This Article is brought to you for free and open access by the Research Centers at DigitalCommons@USU. It has been accepted for inclusion in Wasatch Dendroclimatology Research by an authorized administrator of DigitalCommons@USU. For more information, please contact digitalcommons@usu.edu.

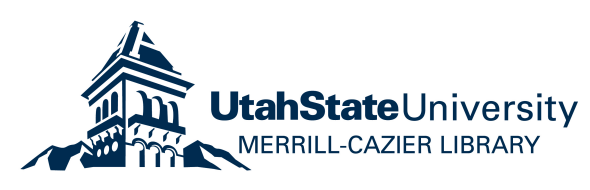




\title{
Feasibility of High-Density Climate Reconstruction Based on Forest Inventory and Analysis (FIA) Collected Tree-Ring Data
}

\author{
R. JUSTIN DERose \\ Forest Inventory and Analysis, Rocky Mountain Research Station, Ogden, Utah \\ SHIH-YU WANG \\ Department of Plants, Soils, and Climate, and Utah Climate Center, Utah State University, Logan, Utah \\ JOHN D. SHAW \\ Forest Inventory and Analysis, Rocky Mountain Research Station, Ogden, Utah
}

(Manuscript received 13 August 2012, in final form 5 November 2012)

\begin{abstract}
This study introduces a novel tree-ring dataset, with unparalleled spatial density, for use as a climate proxy. Ancillary Douglas fir and piñon pine tree-ring data collected by the U.S. Forest Service Forest Inventory and Analysis Program (FIA data) were subjected to a series of tests to determine their feasibility as climate proxies. First, temporal coherence between the FIA data and previously published tree-ring chronologies was found to be significant. Second, spatial and temporal coherence between the FIA data and water year precipitation was strong. Third, the FIA data captured the El Niño-Southern Oscillation dipole and revealed considerable latitudinal fluctuation over the past three centuries. Finally, the FIA data confirmed the quadrature-phase coupling between wet/dry cycles and Pacific decadal variability known to exist for the Intermountain West. The results highlight the possibility of further developing high-spatial-resolution climate proxy datasets for the western United States. (The preliminary FIA data are provided online at http://cliserv. jql.usu.edu/FIAdata/ in both station and gridded format.)
\end{abstract}

\section{Introduction}

Networks of tree-ring data represent important contributions to the study of regional climate, providing in situ evidence of past spatiotemporal climate variability. Tree-ring indices yield annually dated records of climate events from specific locations. In the semiarid western United States, a voluminous literature has reconstructed past climate using tree-ring chronologies, for example, precipitation (Gray et al. 2004b), temperature (Briffa et al. 1992), drought (Cook et al. 2004), and streamflow (Woodhouse et al. 2006).

Classically, the preparation of climatically sensitive treering chronologies requires careful selection of species, sites (e.g., elevation), sample replication, cross dating,

Corresponding author address: Shih-Yu (Simon) Wang, Department of Plants, Soils and Climate, and Utah Climate Center, Utah State University, 4280 Old Main Hill, Logan, UT 84322-4820. E-mail: simon.wang@usu.edu; rjderose@fs.fed.us and chronology development (Fritts 1976). Creating large spatial grids of chronologies for paleoclimate reconstruction is therefore expensive and time consuming. Geographically uniform reconstructions of temperature and precipitation (Fritts 1991) and drought (Cook et al. 2004) have been developed for North America at $2.5^{\circ}$ longitude/latitude resolution, which is coarse considering the complex climate regimes and terrain in the western United States. While the number of chronologies available from the International Tree-Ring Data Bank (ITRDB) for the western United States appears substantial, sparse spatial representation remains for many regions, for example, Utah. Because developing dense spatial networks of classic chronologies over large areas is time and cost prohibitive, examination of possible alternatives should be considered.

Here we introduce a tree-ring dataset collected by the U.S. Forest Service Forest Inventory and Analysis (FIA) Program. The FIA conducts a geographically unbiased, systematic sample across the United States, 


\section{(a) FIA sample location}

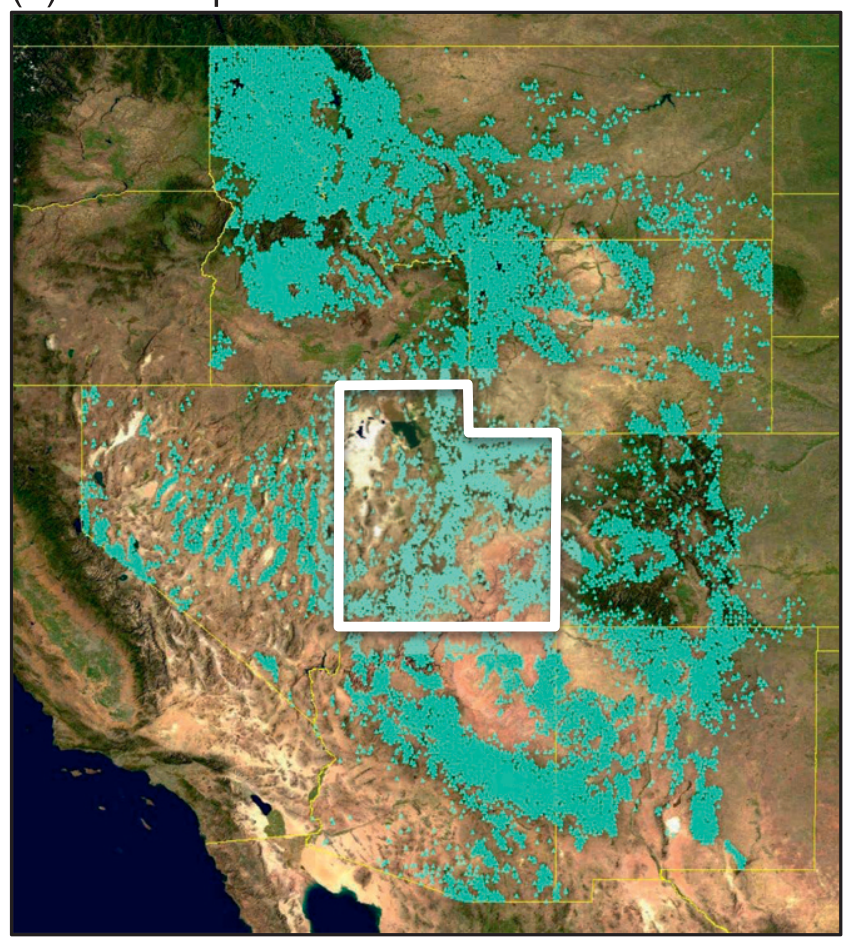

(b) FIA series length
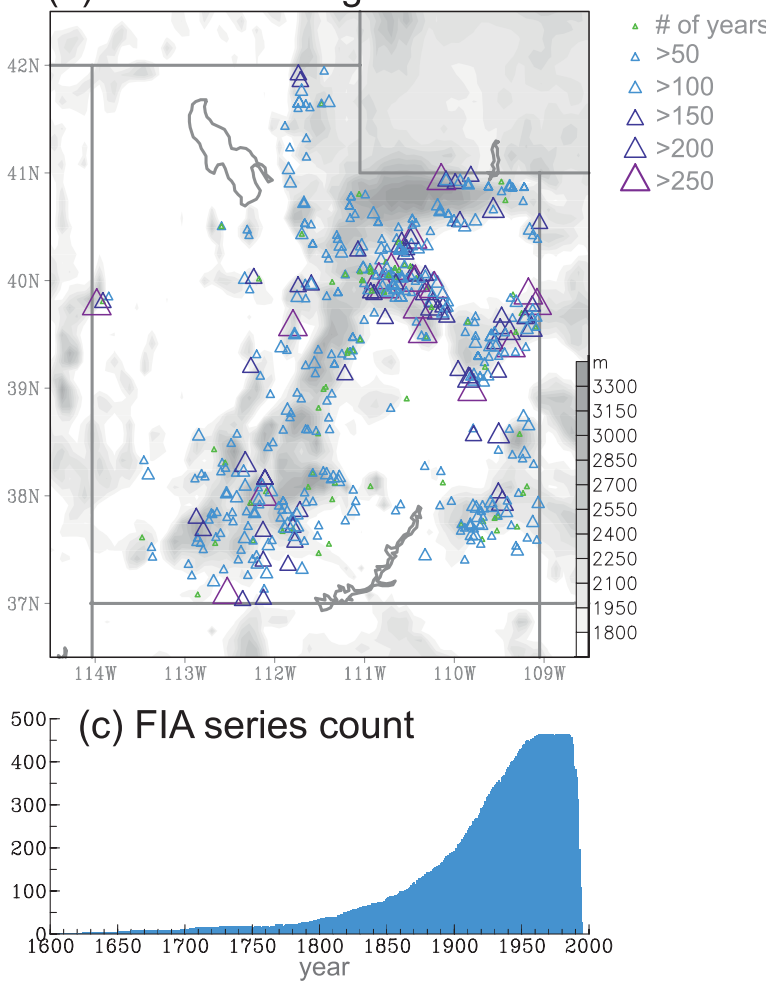

FIG. 1. (a) Location of FIA plots with current available tree-ring series (green dots) in the Intermountain West. (b) Location of FIA data used in this study, with the period of record in years represented by the size and color of triangles (upper right) overlaid with terrain (shading). (c) Number of DF and PP tree-ring series over time within Utah used in this study.

designed to infer population-level estimates of the nation's forests (Smith 2002). The periodic FIA inventory covered all forest types in the Intermountain West at high spatial density and included collection of one or more increment cores from the species that represented the forest type at each location (Fig. 1a). The temporal resolution of the FIA tree-ring data (hereafter FIA data) extends from multiple decades to many centuries (Figs. 1b,c). While the 100-200-yr time span of the FIA data may be short compared to classic chronologies, it is twice as long, and more spatially dense, than most instrumental records in the region. Moreover, the FIA records are largely distributed over unpopulated areas with few stations.

This paper reports the descriptive potential of the gridded FIA data using a subset of tree-ring series [Douglas fir (DF, Pseudotsuga menziessii var. glauca) and piñon pine (PP, Pinus edulis Engelm.)] from Utah (Fig. 1); both species are found at elevations routinely subject to drought (e.g., Gray et al. 2006). Utah is situated on a climate dipole between the southwestern and northwestern United States forced by the El NiñoSouthern Oscillation (ENSO) and the Pacific decadal oscillation (PDO) (Brown and Comrie 2004; Wang et al.
2009). This unique climate regime poses a challenge for spatiotemporal tree-ring analyses and is therefore a desirable test bed for the FIA data. In the following analyses, the FIA data are compared with 1) existing ITRDB chronologies, 2) instrumental records, and 3) known climate patterns. We will demonstrate that the FIA data are in good agreement with both classic chronologies and instrumental records. The analysis also provides corroboration of recently observed variation in climate teleconnections. The results highlight the potential for the use of FIA data in climate research in western North America.

\section{Data sources and treatment}

FIA data were prepared using standard dendrochronological procedures. Each series was crossdated using the closest available species-specific or congener chronology from the ITRDB (Grissino-Mayer and Fritts 1997) or unpublished chronologies before verification with COFECHA (a crossdating quality analysis program; Holmes 1983). Each series was detrended using the "super smoother" (Friedman 1984) to remove the effects of age on growth when present and to accentuate 
(a) FIA and ITRDB sites

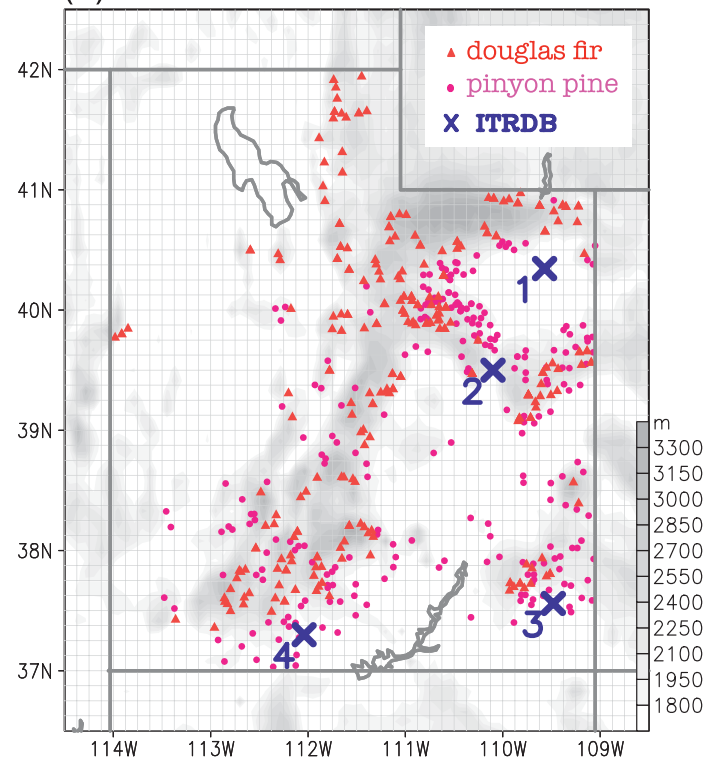

(b) FIA (DF+PP) and ITRDB series

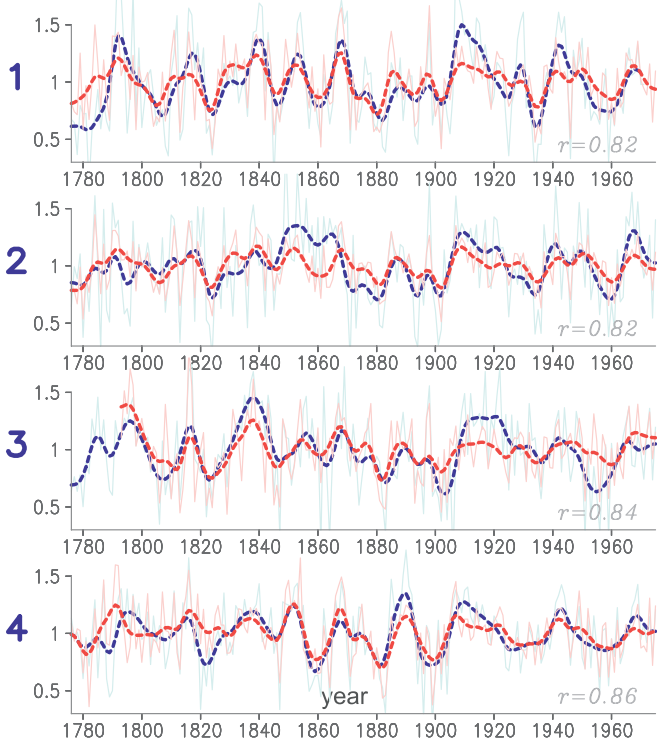

FIG. 2. (a) Site map of the FIA PP (pink dots) and DF (red triangles) samples and four ITRDB chronologies (blue crosses). (b) Chronology series of ITRDB (blue) and FIA (red) at the ITRDB locations, with the light solid lines showing raw data and the dark dashed lines showing the 9-yr moving average. Correlation coefficients labeled in the lower right were calculated between smoothed time series. The four ITRDB chronologies are 1) ut501 (DF; Stockton and Jacoby 1976), 2) ut527 (PP; Pederson et al. 2011), 3) ut529 (DF; Pederson et al. 2011), and 4) ut521 (PP; Grow 1998).

high-frequency (year to year) variability in growth in an unbiased manner across all series. After detrending, raw ring widths were subtracted to create a dimensionless index (Cook et al. 2007). We utilized existing climate reconstructions, including the North American Drought Atlas for the reconstructed Palmer drought severity index (PDSI, $2.5^{\circ} \times 2.5^{\circ}$ resolution; Cook et al. 2004), an AD $1300-2003$ reconstruction of the Niño-3.4 $\left(5^{\circ} \mathrm{N}-5^{\circ} \mathrm{S}\right.$, $170^{\circ} 120^{\circ} \mathrm{W}$ ) sea surface temperature anomaly index (Cook et al. 2009), and an AD 993-1996 reconstruction of the PDO index (MacDonald and Case 2005). We utilized the instrument-based, gridded daily precipitation and temperature data (Maurer et al. 2002).

\section{Analysis and results}

Two primary differences, site selection and sample replication, exist between classic chronologies and the FIA data. For classic chronologies, sites are purposely sampled to maximize climatic signal and temporal length, whereas the FIA grid represents a systematic random sample. Second, with respect to sample replication, classic chronologies consist of multiple averaged series, requiring a large investment in time and resources, whereas FIA data were collected as part of a standardized protocol on plots $\sim 5 \mathrm{~km}$ apart. Using nonclassical tree-ring data is not new, and previous works have demonstrated the usefulness of this approach (Esper et al. 2012; LeBlanc and Terrell 2009; Cook et al. 2001; Graumlich 1993). What is new is the spatial density of the FIA data (Fig. 1). Given this high density, individual series combined within a short distance might correspond to nearby classic chronologies. On the basis of this hypothesis, we applied the Cressman (1959) objective interpolation scheme at $1 / 8^{\circ}$ grid spacing over the FIA data in Utah. The Cressman scheme achieves its result by forcing convergence of the (station) data to the interpolated values using multiple iterations. However, the Cressman scheme does not involve a first-guess field, with the disadvantage of potentially creating spurious values due to interpolation. We gridded the data at $1 / 8^{\circ}$ using four radii of influence- $1 / 8^{\circ}, 1 / 4^{\circ}, 1 / 2^{\circ}$, and $1^{\circ}$ from inner to outer radius-before application with an inversesquare distance weighting $\left(1 / r^{2}\right)$ centered at the site.

\section{a. Comparison with ITRDB records}

We chose four classic chronologies to compare with the FIA data (two DF and two PP; see Figs. 2a,b). The FIA chronologies were constructed by averaging the nine $(3 \times 3)$ grids representing a tree-ring series closest to the ITRDB site. For the raw time series, the variation of the FIA chronologies was typically smaller than that of the ITRDB records (Fig. 2b). Two possible reasons for this difference are 1) that ITRDB records represent 
(a) point-by-point corr: FIA \& Precip

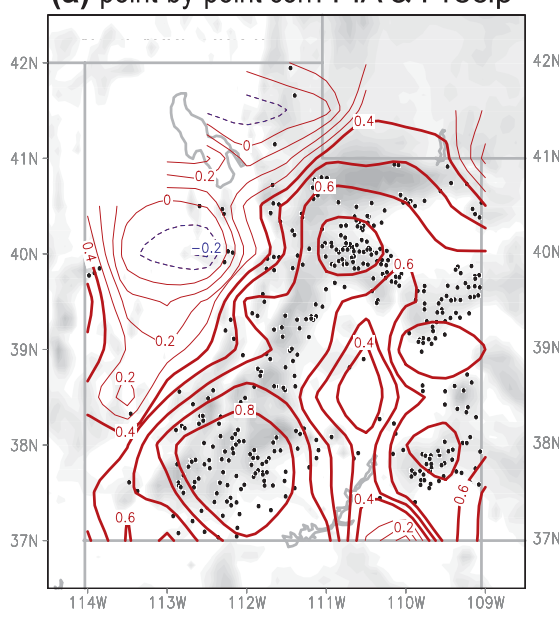

(b) point-by-point corr: FIA \& Temp

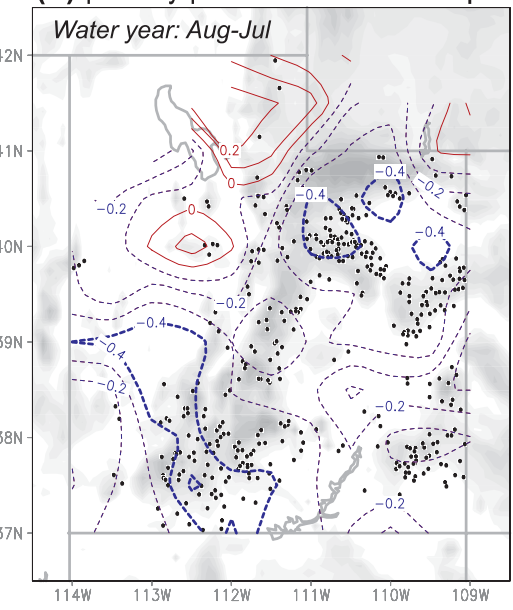

(c) Cross corr:

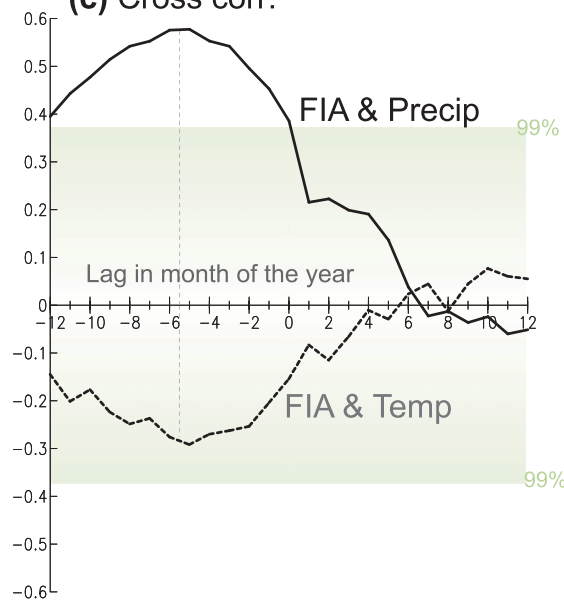

FIG. 3. Point-by-point correlation map (contours) between (a) the FIA data and gridded precipitation and (b) the FIA data and gridded temperature during the water year (August-July) over the period 1950-97, overlaid with terrain (shading) and the FIA sites (black dots). Contours that are significant at the $99 \%$ level are in bold; a nine-point spatial smoothing was applied. (c) Cross correlation between FIA data, annual precipitation (solid line), and annual temperature (dashed line), with a 1-month sliding interval from the previous calendar year ( -12 for January-December of last year) through the current year ( 0 for January-December of this year) to the next year $(+12$ for January-December of next year). The shaded area indicates the $99 \%$ significance level ( $t$ test).

trees that were believed to be particularly sensitive to drought and 2) that the FIA series presented here were averaged from random samples over a $\sim 50-\mathrm{km}^{2}$ area that may have mixed microclimate signals. Nevertheless, decadal fluctuations were present in the smoothed series, where the two datasets exhibited strong coherence $(r=$ 0.82-0.86). Also noteworthy were the decadal and bidecadal cycles present at varying degrees throughout Utah. This feature echoed the predominant low-frequency drought cycles observed over the Intermountain West (Herweijer et al. 2007; Cook et al. 2004) and in Utah (Wang et al. 2010, 2012).

\section{b. Comparison with instrumental records}

A point-by-point correlation map, computed between each grid point of the FIA data and the gridded instrumental precipitation data (1950-95) for the water year (WY; August of the prior year through July), revealed a significant relationship that was particularly prevalent throughout the north-south trending mountains of Utah (Fig. 3a). Negative correlations in the west desert region did not correspond to tree-ring sites and therefore was likely an artifact of extrapolation. The high correlation $(>0.7)$ over central and southern Utah was encouraging and suggested the potential for the FIA data to be used for reconstructing local precipitation. A similar correlation map was created with the gridded WY mean temperature (Fig. 3b). Compared to precipitation, the chronologies were typically negatively correlated with temperature, as has been found for DF (Gray et al. 2004a) and PP (Gray et al. 2004b).
To examine possible correspondence to seasonal climate cycles (reflecting the growing season), we calculated the cross correlation between the FIA data and precipitation/temperature averaged over 12 months with a 1-month time lag, from month -12 (previous calendar year) to month +12 (next calendar year) (Fig. $3 c$ ). This approach was used instead of month-by-month correlations to test for a Utah-wide response. The peak correlation of both precipitation (positive) and temperature (negative) occurred around lag -5 month, indicating that WY precipitation, in particular snowpack, was likely the primary driver of subsequent tree-ring increment for DF and PP in Utah.

\section{c. Comparison with climate teleconnections}

The impact of ENSO on precipitation anomalies produces the so-called North American dipole, encompassing the northwestern/southwestern United States with opposite polarity. However, short-term climate forecasts based on ENSO have frequently failed for Utah (Wood and Warner 2011), as the region lies on the margin of the north-south dipole and therefore is shielded from the direct influence of ENSO. On the basis of the August-July WY from 1950 to 1997, we constructed a one-point correlation map of precipitation with ENSO, defined as the December-February (DJF) mean Niño-3.4 sea surface temperature anomaly (SSTA) index (obtained online at http://www.cpc.ncep.noaa.gov/data/indices/ersst3b. nino.mth.81-10.ascii). The resultant map depicted the dipole across Utah, oriented northwest-southeast (Fig. 4a). ENSO correlated with the FIA data depicted a similar pattern 
(a) corr. ENSO \& Precip

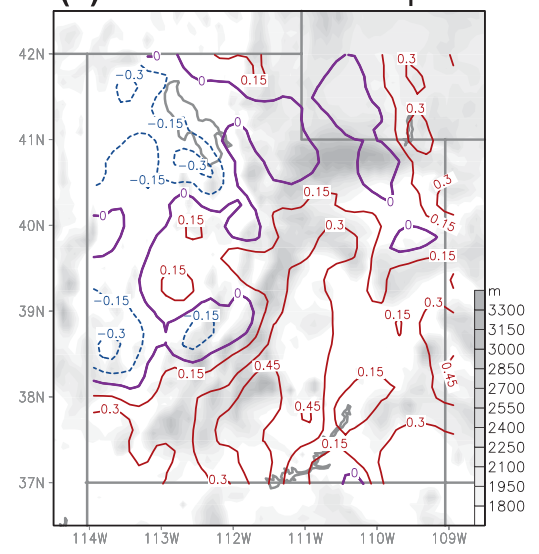

(b) corr. ENSO \& FIA

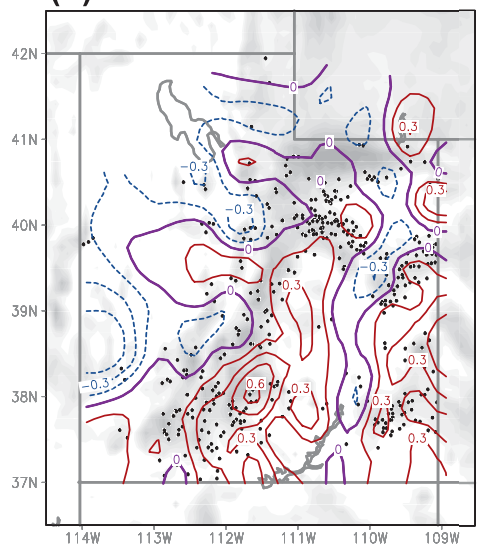

(c) sliding corr. ENSO \& FIA

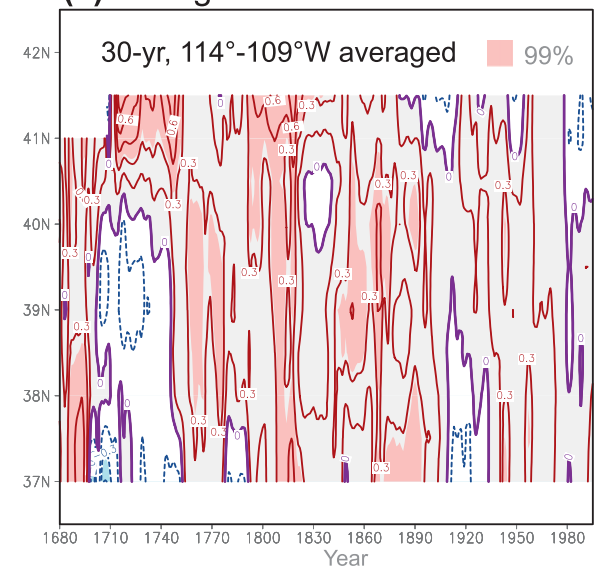

FIG. 4. One-point correlation map (contours) between the DJF Niño-3.4 index with (a) the water year precipitation, and (b) the FIA data during the period 1950-97, overlaid with terrain (shading) and the FIA sites [black dots in (b)]. (c) Correlation between the FIA data and the reconstructed Niño-3.4 index (Cook et al. 2009) within a 30-yr sliding window averaged across the longitudes of Utah from 1680 (indicating 1651-80) to 1995 (indicating 1966-95). Values greater than the 99\% significance level (absolute values $>0.372$ ) are shaded in pink. For all panels, zero contours are highlighted in purple.

with similar orientation (Fig. 4b). Agreement between Figs. $4 \mathrm{a}$ and $4 \mathrm{~b}$ suggested reasonable representation of local climate anomalies by the FIA data with regard to ENSO.

One advantage of the FIA data is that it can extend the depiction of ENSO impact further into the past by computing a latitude-time section of the sliding correlation across Utah (Fig. 4c). This involved 1) computing the correlation map of the FIA chronologies with the reconstructed DJF Niño-3.4 index (Cook et al. 2009) using a moving 30 -yr window based on the last year (e.g., 1980 indicates the $1951-80$ period) and 2) averaging the correlations zonally across Utah longitudes $114^{\circ}-109^{\circ} \mathrm{W}$. The resultant sliding correlations exhibited distinct changes over time (Fig. 4c). While the 30 years from 1950 onward indeed exhibited a transition of ENSO impact (i.e., zero correlation) across central Utah, this transition was not steady during the past $300+$ years. In fact, for the period from 1750 to 1900 , the correlation was primarily positive with episodes of significant values, suggesting that ENSO impacted climate anomalies uniformly throughout the state, instead of just a portion, as was the case post-1950. Past studies (Hidalgo and Dracup 2003; Brown and Comrie 2004) have also noted that the ENSO climate impact in this region has fluctuated in the past, likely modulated by the PDO.

\section{d. Supportive evidence of the decadal cycles}

Although Utah is only marginally affected by prominent climate modes like ENSO and PDO (for the past century), recent studies have uncovered pronounced wet/ dry cycles that are unique to the Intermountain West, with spectral peaks at $\sim 25$ and $10-15$ yr. Focusing on the Great Salt Lake (GSL) in Utah, Wang et al. (2010, 2012) found that the hydrological factors controlling the GSL elevation respond to a type of Pacific teleconnection that is induced at the transition point of the so-called interdecadal Pacific oscillation (IPO; Folland et al. 2002), which exhibits signals also found in PDO. The transition lies approximately halfway between the warmest and coldest SSTA in the central tropical Pacific, corresponding to the extreme IPO/PDO phases. At those transition points, a distinctive teleconnection emerges, forming atmospheric circulation anomalies over the Gulf of Alaska; this directs moisture flux across the Great Basin and subsequently drives wet/dry conditions over Utah. The IPO/PDO life cycle therefore modulates local droughts and pluvials in a quarter-phase manner.

To examine whether the FIA data capture this known decadal variability, the data were projected onto a coarser grid mesh $\left(0.5^{\circ} \times 0.5^{\circ}\right)$ with a $0.5^{\circ}$ radius of influence for the period of 1800-1995, after which an empirical orthogonal function (EOF) was computed. The first EOF eigenvector (EOF1) was dominant, explaining $33.5 \%$ of the total variance, and was uniformly distributed throughout the state (Fig. 5a), which suggested the FIA data have strong spatial fidelity. For comparison we analyzed the PDSI dataset (Cook and Krusic 2004), averaged from the four Utah grid points (Fig. 5a). Although both datasets were derived from tree rings, they are wholly independent, and each was collected using completely different designs. The first principal component (PC1) of the FIA data and the PDSI, smoothed by a 3-yr running mean, were coherent 
(a) EOF1 FIA: $33.5 \%$

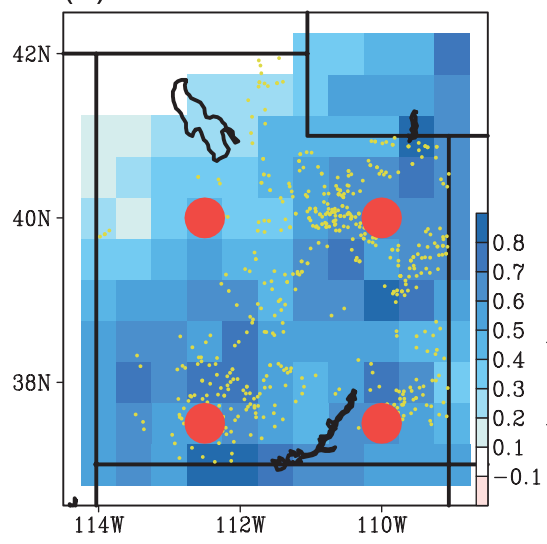

(b) PC1 FIA

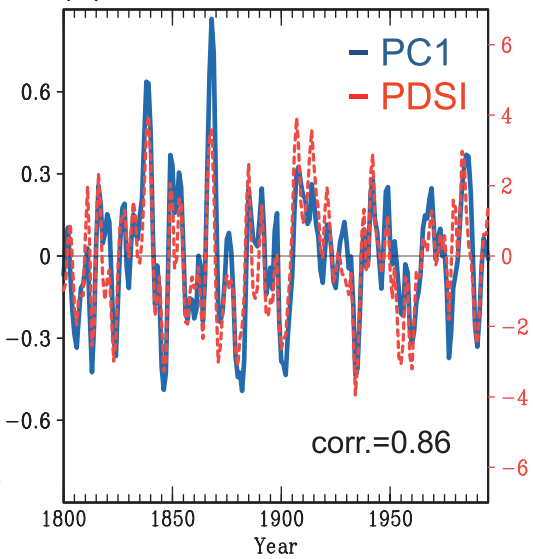

(c) Cross corr. w/ PDO

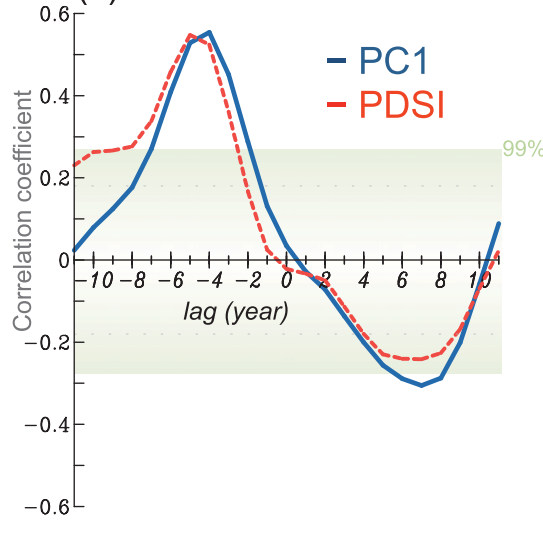

FIG. 5. (a) EOF1 of the gridded FIA data during the period 1800-1995 overlaid with the PDSI grids (red dots; Cook and Krusic 2004) and FIA sites (yellow dots). (b) PC1 series (blue solid line) overlaid with the four-point average of the PDSI (red dashed line), with their correlation coefficient indicated in the bottom right and both smoothed by a 3-yr moving average. The two smoothed time series showed strong coherence $(r=0.86)$. (c) Cross correlation of the reconstructed PDO index (MacDonald and Case 2005) with PC1 (solid blue line) and the PDSI (red dashed line); for example, lag -4 means that PC1/PDSI lags PDO by $4 \mathrm{yr}$. The shaded area indicates the $99 \%$ significance level after taking into consideration the reduction in degrees of freedom from the moving average.

$(r=0.86$, Fig. 5b). Decadal variability was present in both the PC1 and the PDSI, while their power spectra (not shown) revealed a primary peak between 10 and $15 \mathrm{yr}$ and a secondary peak around $25 \mathrm{yr}$, consistent with previous studies (Wang et al. 2010, 2012).

Since the IPO reconstruction is not available, we correlated a PDO index (MacDonald and Case 2005) with the FIA data PC1 and the PDSI data (Fig. 5b). Significant correlations existed, with the PDO leading the PC1 by 4 yr (and leading the PDSI by 5 yr). A secondary correlation peak was found, with the inverse PDO phase lagging both time series by $7-8$ yr. Combined, these lead/lag times confirmed that the decadal wet/dry cycles, as previously noted, are present in the FIA data and are linked to the PDO. Furthermore, with the simultaneous correlation near zero, these wet/dry cycles are quarter-phase shifted with the PDO. This result is consistent with - and supportive of - the quadraturephase coupling of the PDO with the wet/dry cycles in this region (Wang et al. 2009) and the associated "transitionphase teleconnection" mechanism proposed by Wang et al. $(2010,2012)$.

\section{Conclusions}

We investigated the potential for FIA data to be used as a climate proxy for the western United States using data from Utah as a test case. Although different than classic tree-ring chronologies, the FIA locations cover a broad area with substantially higher spatial density than existing chronologies or station data, allowing more detailed local climate information to be extracted. By grouping FIA data within fixed grid spacing, we showed strong relationships with ITRDB data, especially for decadal variability. The FIA data were most sensitive to WY precipitation, indicated by the correlation with instrumental data, which oftentimes exceeded 0.8. The FIA data reproduced the known dipole of precipitation anomalies associated with ENSO. Moreover, we revealed considerable latitudinal fluctuation of the ENSO dipole over the past 300 years, suggesting spatiotemporal instability of this climate pattern. Finally, the FIA data confirmed the recently discovered quadraturephase coupling between the pronounced wet/dry cycles and Pacific decadal variability.

These results highlight the feasibility of FIA data to be developed into high-resolution sets of climate reconstructions, such as precipitation or drought. Full preparation of the FIA tree-ring series analyzed herein represents a multiple-year effort (they are provided online at http://cliserv.jql.usu.edu/FIAdata/ in both station and gridded formats). Future work will seek to enhance the FIA data representation throughout the Intermountain West (indicated in Fig. 1a). Upon completion, a very high-resolution, gridded proxy climate dataset will be reported and made available for the research community.

Acknowledgments. Unpublished chronologies were provided by Matt Bekker, Eric Allen, Connie Woodhouse, and Jeff Lukas. Comments offered by Roger Kjelgren are appreciated. This research was supported by the 
Bureau of Reclamation Project R11AC81456 and approved by the Utah Agricultural Experiment Station, Utah State University, as journal paper number 8448.

\section{REFERENCES}

Briffa, K. R., P. D. Jones, and F. H. Schweingruber, 1992: Tree-ring density reconstructions of summer temperature patterns across western North America since 1600. J. Climate, 5, 735-754.

Brown, D. P., and A. C. Comrie, 2004: A winter precipitation 'dipole' in the western United States associated with multidecadal ENSO variability. Geophys. Res. Lett., 31, L09203, doi:10.1029/2003GL018726.

Cook, E. R., and P. J. Krusic, cited 2004: The North American drought atlas. Lamont-Doherty Earth Observatory. [Available online at http://iridl.ldeo.columbia.edu/SOURCES/.LDEO/. TRL/.NADA2004/.pdsi-atlas.html.]

_ J. J. Glitzenstein, P. J. Krusic, and P. A. Harcombe, 2001: Identifying functional groups of trees in west Gulf Coast forests (USA): A tree-ring approach. Ecol. Appl., 11, 883903.

— C. A. Woodhouse, C. M. Eakin, D. M. Meko, and D. W. Stahle, 2004: Long-term aridity changes in the western United States. Science, 306, 1015-1018.

—, P. J. Krusic, R. H. Holmes, and K. Peters, cited 2007: ARSTAN Version 41d. Columbia University. [Available online at http://www.ldeo.columbia.edu/tree-ring-laboratory/ resources/software.]

— R. D. D'Arrigo, and K. J. Anchukaitis, cited 2009: Tree ring 500 year ENSO index reconstructions. IGBP PAGES/World Data Center for Paleoclimatology Data Contribution Series 2009-105, NOAA/NCDC Paleoclimatology Program. [Available online at ftp://ftp.ncdc.noaa.gov/pub/data/paleo/treering/ reconstructions/nino-cook2008.txt.]

Cressman, G. P., 1959: An operational objective analysis system. Mon. Wea. Rev., 87, 367-374.

Esper, J., M. Benz, and N. Pederson, 2012: Influence of wood harvest on tree-ring time-series of Picea abies in a temperate forest. For. Ecol. Manage., 284, 86-92.

Folland, C. K., J. A. Renwick, M. J. Salinger, and A. B. Mullan, 2002: Relative influences of the interdecadal Pacific Oscillation and ENSO on the South Pacific convergence zone. Geophys. Res. Lett., 29, 1643, doi:10.1029/2001GL014201.

Friedman, J. H., 1984: A variable span smoother. Tech. Rep. 5, Laboratory for Computational Statistics, Department of Statistics, Stanford University, Stanford, CA, 30 pp. [Available online at http://www.slac.stanford.edu/cgi-wrap/getdoc/slac-pub3477.pdf.]

Fritts, H. C., 1976: Tree Rings and Climate. Academic Press, 567 pp.

_- 1991: Reconstructing Large-Scale Climatic Patterns from Tree Ring Data: A Diagnostic Analysis. University of Arizona Press, 286 pp.

Graumlich, L. J., 1993: Response of tree growth to climatic variation in the mixed conifer and deciduous forests of the upper Great Lakes region. Can. J. For. Res., 23, 133-143.

Gray, S. T., C. L. Fastie, S. T. Jackson, and J. L. Betancourt, 2004a: Tree-ring-based reconstructions of precipitation in the Bighorn Basin, Wyoming, since 1260 A.D. J. Climate, 17, 38553865.

_, S. T. Jackson, and J. L. Betancourt, 2004b: Tree-ring based reconstructions of interannual to decadal scale precipitation variability for northeastern Utah since 1226 AD. J. Amer. Water Resour. Assoc., 40, 947-960.

, J. L. Betancourt, S. T. Jackson, and R. G. Eddy, 2006: Role of multidecadal climate variability in a range extension of pinyon pine. Ecology, 87, 1124-1130.

Grissino-Mayer, H. D., and H. C. Fritts, 1997: The International Tree-Ring Data Bank: An enhanced global database serving the global scientific community. Holocene, 7, 235-238.

Grow, D. W., cited 1998: Yovimpa Point, Bryce Canyon, Utah. National Climatic Data Center, Asheville, NC, digital media. [Available online at http://www.ncdc.noaa.gov/paleo/treering. html.]

Herweijer, C., R. Seager, E. R. Cook, and J. Emile-Geay, 2007: North American droughts of the last millenium from a gridded network of tree-ring data. J. Climate, 20, 1353-1376.

Hidalgo, H. G., and J. A. Dracup, 2003: ENSO and PDO effects on hydroclimatic variations of the Upper Colorado River basin. J. Hydrometeor., 4, 5-23.

Holmes, R. L., 1983: Computer-assisted quality control in tree-ring dating and measurement. Tree-Ring Bull., 43, 69-78.

LeBlanc, D. C., and M. A. Terrell, 2009: Radial growth response of white oak to climate in eastern North America. Can. J. For. Res., 39, 2180-2192.

MacDonald, G. M., and R. A. Case, 2005: Variations in the Pacific decadal oscillation over the past millennium. Geophys. Res. Lett., 32, L08703, doi:10.1029/2005GL022478.

Maurer, E. P., A. W. Wood, J. C. Adam, D. P. Lettenmaier, and B. Nijssen, 2002: A long-term hydrologically based dataset of land surface fluxes and states for the conterminous United States. J. Climate, 15, 3237-3251.

Pederson, G. T., and Coauthors, 2011: The unusual nature of recent snowpack declines in the North American Cordillera. Science, 333, 332-335.

Smith, W. B., 2002: Forest inventory and analysis: A national inventory and monitoring program. Environ. Pollut., 116, 233-242.

Stockton, C. W., and G. C. Jacoby, 1976: Long-term surface-water supply and streamflow trends in the Upper Colorado River basin based on tree-ring analyses. Lake Powell Research Project Bulletin 18, 70 pp. [Available online at http://www. gcmrc.gov/library/reports/physical/hydrology/Stockton1976. pdf.]

Wang, S.-Y., R. R. Gillies, J. Jin, and L. E. Hipps, 2009: Recent rainfall cycle in the Intermountain Region as a quadrature amplitude modulation from the Pacific decadal oscillation. Geophys. Res. Lett., 36, L02705, doi:10.1029/2008GL036329.

,,--- , and - 2010: Coherence between the Great Salt Lake level and the Pacific quasi-decadal oscillation. J. Climate, 23, 2161-2177.

,-- , and T. Reichler, 2012: Multi-decadal drought cycles in the Great Basin recorded by the Great Salt Lake: Modulation from a transition-phase teleconnection. J. Climate, 25, 17111721.

Wood, A. W., and K. Warner, 2011: Development of a seasonal climate and streamflow forecasting testbed for the Colorado River Basin. Proc. 36th Climate Diagnostic and Prediction Workshop, Fort Worth, TX, NOAA, 101-105. [Available online at http://www.nws.noaa.gov/ost/climate/STIP/36CDPW/ 36cdpw-awood.pdf.]

Woodhouse, C. A., S. T. Gray, and D. M. Meko, 2006: Updated streamflow reconstructions for the Upper Colorado River basin. Water Resour. Res., 42, W05415, doi:10.1029/ 2005 WR004455. 